DOI: $10.14451 / 1.191 .124$

\title{
СРЕДНЕСРОЧНЫЕ ЭКОНОМИЧЕСКИЕ ТЕНДЕНЦИИ ОБРАБАТЫВАЮЩЕЙ ПРОМЫШЛЕННОСТИ
}

\section{(c) 2020 Овсянников Роман Юрьевич}

соискатель кафедры экономики и управления предприятиями и производственными комплексами Санкт-Петербургский государственный экономический университет, Россия, Санкт-Петербург

E-mail: r.ovsyannikov@academprofi.ru

В настоящей публикации автором рассмотрены среднесрочные тенденции мировой обрабатывающей промышленности, определяющие трансформацию структуры факторов производства. Выявлена и объяснена природа волновой динамики производительности обрабатывающих предприятий. Работа выполнена в рамках плана исследований научной школы СПбГЭУ «Экономика, организация и управление предприятиями, отраслями, комплексами; управление инновациями; экономика оборонно-промышленного комплекса» (руководитель - профессор Карлик А.Е.).

Ключевые слова: экономика, обрабатывающая промышленность.

Новая волна исследования экономических тенденций обрабатывающей промышленности (2010-2020 год) сменила фокус от пространственных аспектов (размещение, локализация производств) к трансформации «факторов производства» в условиях «инновационной», «знаний», «зеленой», «устойчивости», «цифровой» и других «экономик» (Ивантер В.В. [1]). Причем реальные, практические процессы трансформации производительных сил и производственных отношений в обрабатывающей промышленности значительно опережают их анализ в экономических исследованиях - российские и зарубежные публикации отражают ретроспективу «постфактум» (Chryssolouris G. [2]). Задачей экономической науки автор видит формулировку перспектив, позволяющих инвесторам и менеджменту формировать стратегии, построенные на новых вызовах - глобальных фактоpax конкурентоспособности. Соответственно, в настоящей публикации автор скомпилировал и формализовал солидарно видимые учеными, бизнес-аналитиками среднесрочные тенденции, построенные на анализе перспектив, Форсайте структуры производственных факторов глобальной обрабатывающей промышленности и ее внешней среды. Анализ построен на исследовательских отчетах (CBRE [3], KPMG [4], Delloite [5], WEF [6], OECD [7], EC [8]) и других), что позволило выделить 3 тенденции, обсуждаемые в настоящей публикации.

«Консолидация мировой обрабатывающей промышленности», так автор формулирует 1-ую тенденцию, выражающую глобализацию процессов производства и потребления (Фомина Н.Е. и др. [9]). 3 страны концентрируют 48\% [7] мирового сектора обрабатывающих производств: Китай $-20 \%$, США - 18\%, Япония $10 \%$. Концентрируется и потребление - это видно через рост темпов мирового экспорта $-6,5 \%$ среднегодовые, табл. 1. «...Мир становится более интегрированным, среднемировая доля экспорта в ВВП выросла с 23\% (1975) до 43\% (2017)» (OECD [7]).

Таблица 1. Объемы и темпы роста мирового и по группам экономик экспорта. Интерпретировано по WEF [6]. Обозн.: ВА - вертикальные распределения; СТP - среднегодовые темпы.

\begin{tabular}{|l|l|l|l|l|l|l|}
\hline Мир в разрезе групп & 2005 & 2010 & 2015 & 2018 & BA & CTP \\
\hline Общемировой экспорт & 2657,9 & 3921,3 & 4962,6 & 5845,1 & $100 \%$ & \\
\hline темпы изменения & \multicolumn{7}{|l|}{$8,9 \%$} & $-4,5 \%$ & $7,7 \%$ & & $\mathbf{6 , 5 \%}$ \\
\hline В т. ч. по типам (WEF) экономик: \\
\hline «Развивающиеся» & 613,1 & 1096,0 & 1470,6 & 1738,1 & $30 \%$ & \\
\hline темпы изменения & & $21,3 \%$ & $-2,3 \%$ & $9,3 \%$ & & $8,7 \%$ \\
\hline «Транзитивные» & 53,4 & 97,9 & 107,2 & 137,2 & $2 \%$ & \\
\hline темпы изменения & & $10,6 \%$ & $-15,7 \%$ & $12,4 \%$ & & $8,5 \%$ \\
\hline «Развитые» & 1991,4 & 2727,4 & 3384,7 & 3969,7 & $\mathbf{6 8 \%}$ & \\
\hline темпы изменения & & $4,6 \%$ & $-5,0 \%$ & $6,8 \%$ & & $5,7 \%$ \\
\hline
\end{tabular}


Наиболее выражена данная тенденция в расслоении структуры экспорта между странами с «развитыми» и «транзитивными», «развивающимися» экономиками. Первые консолидировали 68\% мирового экспорта, в структуре которого 80\% относится к обрабатывающему сектору с инновационной составляющей 43\% [8]. Встречная тенденция - экспорт «развивающихся» стран (30\% - BA), построенный на товарной группе «сырье и продукты первичной переработки» (более $80 \%$ в структуре). В социальном и промышленном потреблении всех стран формируется единая модель потребления, задаваемая технологическими лидерами развитых стран (Hult G. T.M. и др. [10]). Причем тенденция наращивает темпы пропорционально увеличению доли мирового рынка, охватываемого глобальными лидерами обрабатывающей промышленности. Встречно ослабевает конкуренция на национальных и международных рынках, глобальные лидеры формируют вертикальные цепи (сети) добавленной стоимости.

Наблюдается поляризация макроэкономических стратегий развитых и развивающихся экономик в отношении обрабатывающей промышленности. В рамках продуктовой специализации (RAND [11]) промышленность развитых стран стремится максимизировать долю мирового рынка, реализуя экономический эффект снижения предельных издержек производства. Страны, относящиеся к группам развивающихся и транзитивных экономик (классификация WEF), при наличии стратегии присутствия в мировом товарообороте, «вынуждены искать свое место в вертикальных цепочках добавленной стоимости» [9]. При наличии значимого объема внутреннего рынка потребления (страны BRIC) возможно применение оборонительной страте- гии, построенной на экспортных барьерах, формировании нормативных требований к государственным закупкам и других способах защиты национальной обрабатывающей промышленности. Но объективны ограничения данной стратегии: применима только к отраслям, связанным с экономической или оборонной безопасностью. В любом случае, вызов, стоящий перед национальной обрабатывающей промышленностью, формулируется как необходимость выработки стратегии в рамках консолидации мирового рынка, увеличения ее темпов в среднесрочной перспективе.

Тенденция 2: Инновации, моральная и научно-техническая новизна продукции - ключевой фактор глобальной конкурентоспособности обрабатывающей промышленности. Именно «инновации» Chryssolouris G. [2], по результатам опроса субъектов обрабатывающего сектора, определяет первичным в структуре драйверфакторов экономического роста - табл. 2 .

На микроуровне научно-техническая (моральная) новизна потребительской и промышленной продукции обрабатывающей промышленности определяется ключевым элементом спроса, что сокращает жизненный цикл продуктов и увеличивает темпы обновления ассортимента. Соответственно, промышленные предприятия инвестируют в НИОКР от 3\% (низкотехнологичный) до 17\% (высокотехнологичный) от годового товарооборота, а стратегии научно-технического развития и программы перспективных разработок формируются на 15-20 лет [12]. А в макроэкономическом разрезе среднемировой уровень (по совокупности частных и государственных) инвестиций в НИОКР составляет 2,27\% ВВП, табл. 3. Причем наблюдается и приращение уровня совокупных годовых

Таблица 2. Драйвер-факторы экономического роста обрабатывающей промышленности (Chryssolouris G. и др. [2]).

\begin{tabular}{|l|l|}
\hline Драйверы развития обрабатывающей промышленности & $\begin{array}{l}\text { Ранг (10 - } \\
\text { макс.) }\end{array}$ \\
\hline Инновации & 9,22 \\
\hline Стоимость труда и материалов & 7,67 \\
\hline Стоимость энергии и тарифная политика & 7,31 \\
\hline Экономическая, торговая, финансовая и налоговая системы & 7,26 \\
\hline Качество инженерной инфраструктуры & 7,15 \\
\hline Государственные инвестиции в производство и инновации & 6,62 \\
\hline Нормативно-правовая система & 6,48 \\
\hline Сеть поставщиков & 5,91 \\
\hline Динамика локального рынка & 4,01 \\
\hline Качество и доступность медицинской помощи & 1,81 \\
\hline
\end{tabular}


инвестиций $+0,007 \%$ ВВП (средняя по миру). А у развитых стран темпы еще более значительны 0,05-0,1\%. Встречная тенденция - значительный рост рынка объектов интеллектуальной собственности, в первую очередь франшиз и лицензий, связанных с новыми технологиями. В мировом обмене технологиями, конечно, 83,48\% оборота сконцентрировано в странах с «высоким доходом» экономиках (классификация Мирового Банка, далее WB), а среднегодовой прирост составляет $1 \%$. Конечно, на открытом рынке интеллектуальной собственности предлагаются технологии предыдущего поколения [12], а новое поколение научно-технических решений лидеры обрабатывающей промышленности вводят в собственный инновационно-инвестиционный цикл.

В рамках этой тенденции развивающиеся страны поставлены перед альтернативой приобретения франшиз и лицензий предыдущего поколения, либо допуска на внутренний рынок импортной продукции актуального технологического уровня. В условиях значительных темпов прироста инвестиций в НИОКР развитых стран, возможность реализации стратегии самостоятельного «инновационного прорыва» автор ставит под сомнение. И вопрос не только в недостаточности инвестиционного ресурса (в частности, 1\% ВВП инвестиции в НИОКР России), а скорее в факторе времени, которое нужно для создания человеческого капитала в секторе исследований и разработок, формирования инновационных инфраструктуры и системы взаимодействия науки и промышленности.

Тенденция 3: «Цифровая экономика» наиболее сильный драйвер развития, принципиальной трансформации производительных сил и производственных отношений обрабатывающей промышленности. Содержательным ядром которой являются «...мобильность, облачные вычисления, интернет-вещи, искусственный интеллект и анализ больших данных» (OECD, [7]).

Экономический эффект внедрения цифровых решений в обрабатывающей промышленности сводится к увеличению производительности - росту добавленной стоимости на 1 работающего (Rai A. и др. [13]), среднегодовые темпы роста которой в развитых странах от 2,3\% до $3 \%$.

И это вполне логично в контексте теории экономики промышленности: при незначительной динамике валового товарооборота (в условиях консолидированных рынков - тенденция 1) усилия менеджмента обрабатывающих предприятий концентрируются на сокращении издержек, в первую очередь основного производственного цикла.

Авторский анализ динамики производительности обрабатывающей промышленности в ретроспективе 13 лет позволил обнаружить

Таблица 3. Инновационность (затраты на НИОКР в ВВП,\%) экономики отдельных стран, пятилетняя динамика $(\Delta, \%)$ и ее средняя (CTP,\%). Рассчитано по WB.

\begin{tabular}{|l|l|l|l|l|l|l|}
\hline Страны & 2000 & 2005 & 2010 & 2015 & 2018 & СТР \\
\hline Среднемировой & 2,06 & 1,97 & 2,02 & 2,09 & $\mathbf{2 , 2 7}$ & \\
\hline$\Delta$ & 0,04 & $-0,05$ & 0,03 & 0,04 & 0,09 & $\mathbf{0 , 0 3}$ \\
\hline Австрия & 1,89 & 2,37 & 2,73 & 3,05 & 3,17 & \\
\hline$\Delta$ & 0,19 & 0,26 & 0,15 & 0,12 & 0,04 & 0,15 \\
\hline Германия & 2,40 & 2,43 & 2,71 & 2,91 & 3,09 & \\
\hline$\Delta$ & 0,12 & 0,01 & 0,12 & 0,07 & 0,06 & 0,08 \\
\hline Евросоюз & 1,81 & 1,78 & 1,99 & 2,13 & 2,21 & \\
\hline$\Delta$ & 0,04 & $-0,02$ & 0,12 & 0,07 & 0,04 & 0,05 \\
\hline Финляндия & 3,25 & 3,33 & 3,73 & 2,89 & 2,77 & \\
\hline$\Delta$ & 0,32 & 0,03 & 0,12 & $-0,22$ & $-0,04$ & 0,04 \\
\hline Нидерланды & 1,79 & 1,77 & 1,70 & 1,98 & 2,16 & \\
\hline$\Delta$ & $-0,03$ & $-0,01$ & $-0,04$ & 0,16 & 0,09 & 0,04 \\
\hline Россия & 1,05 & 1,07 & 1,13 & 1,10 & $\mathbf{0 , 9 9}$ & \\
\hline$\Delta$ & 0,09 & 0,02 & 0,06 & $-0,03$ & $-0,10$ & 0,01 \\
\hline США & 2,63 & 2,52 & 2,74 & 2,72 & 2,84 & \\
\hline$\Delta$ & 0,07 & $-0,04$ & 0,09 & $-0,01$ & 0,04 & 0,03 \\
\hline Китай & 0,89 & 1,31 & 1,71 & 2,07 & 2,19 & \\
\hline$\Delta$ & 0,59 & 0,46 & 0,31 & 0,21 & 0,06 & 0,32 \\
\hline
\end{tabular}

Источник: Режим доступа: https://data.worldbank.org 12.12.2019-24.11.2020. 
Таблица 4. Среднегодовой рост производительности (\%) обрабатывающей промышленности, OECD [7].

\begin{tabular}{|l|l|l|l|l|l|l|l|}
\hline Страны & 1996 & 2000 & 2005 & 2010 & 2015 & 2019 & $95-2019$ \\
\hline Австрия & 3,5 & 6,6 & 5,4 & 9,7 & 0,4 & $-1,1$ & 2,90 \\
\hline Дания & $-2,5$ & 5,1 & 0,2 & 13,9 & $-1,8$ & 3,5 & 3,15 \\
\hline Финляндия & 3,0 & 12,0 & 3,6 & 12,8 & 1,9 & 3,4 & 3,50 \\
\hline Франция & 2,0 & 4,7 & 3,9 & 7,3 & 2,8 & $-0,4$ & 2,73 \\
\hline Германия & $-0,3$ & 6,0 & 3,4 & 21,4 & 0,6 & $-3,8$ & 1,99 \\
\hline Израиль & 6,1 & 11,6 & 4,8 & 13,8 & $-1,8$ &.. & 2,31 \\
\hline Италия & 0,9 & 3,6 & 1,6 & 13,7 & 3,5 & $-0,8$ & 1,15 \\
\hline Япония & 5,7 & 7,7 & 7,2 & 17,4 & 4,9 &.. & 3,00 \\
\hline Нидерланды & 3,3 & 5,1 & 5,2 & 7,5 & 0,6 & $-1,5$ & 2,61 \\
\hline Норвегия & 2,9 & 2,6 & 3,4 & 6,2 & $-1,7$ & 1,4 & 1,88 \\
\hline Польша & $-2,0$ & 4,6 & 1,3 & 16,0 & 3,9 & 7,7 & 4,97 \\
\hline Швеция & 3,8 & 8,9 & 4,2 & 23,9 & 7,8 & 1,2 & 3,84 \\
\hline Швейцария & 3,3 & 2,3 & 3,2 & 9,5 & 1,3 & 2,1 & 2,80 \\
\hline Великобритания & $-0,6$ & 5,5 & 4,8 & 7,1 & $-1,0$ & $-0,6$ & 1,93 \\
\hline США &.. &.. & 4,4 & 6,4 & $-1,0$ &.. & $\mathbf{2 , 6 7}$ \\
\hline Европейский Союз & 0,4 & 6,0 & 3,1 & 13,8 & 3,3 & $-0,7$ & $\mathbf{2 , 3 6}$ \\
\hline & & & & &
\end{tabular}

циклическую, волновую динамику. Природу циклов автор объясняет с позиции распространения прорывных решений в области инфокоммуникаций, поколений цифровых решений (совокупности оборудования и программных средств). В среднесрочной ретроспективе объективны 2-е волны производительности, показательные для обрабатывающей промышленности США и Евросоюза, рис. 1.

I волна с пиком 2003-2005 года для обрабатывающей промышленности являлась скорее «отраженной» - среднегодовые темпы роста производительности составили 5-10\%. Развитие инфокоммуникационных технологий дало толчок сферам деятельности, связанным с обращением информации (банки, информационные сервисы, интерфейсы и т.п.), что косвенно повлияло на эффективность основных и обеспечивающих процессов обрабатывающей промышленности.

Впрочем, и внутренние процессы предприятий промышленности, связанные с обработкой и движением информации (проектирование, инжиниринг, менеджмент, финансы, логистика, маркетинг и другие), перешли на новый уровень операционной эффективности, повлияв на производительность производственного цикла. Исчерпав потенциал цифровых решений, производительность снизилась и усугубилась кризисом в финансовом секторе 2008 года. I волна создала объективный толчок автоматизации рабочих мест обрабатывающей промышленности, табл. 5. Обратим внимание, что Дания указывает на
100\% автоматизацию всех рабочих мест основного производственного и вспомогательного цикла промышленных предприятий при росте производительности в том же периоде 3,15\% (табл. 4).

Впрочем, пик волны отражает скорее накопленный, кумулятивный эффект внедрения цифровых решений с 1995 года, когда предложение новых информационных технологий значительно опережало инженерно-технологическое осмысление потенциала их использования в производственном цикле обрабатывающей промышленности (Rai A. и др. [13]).

Если первую волну мы понимаем как «отраженную», то вторая сформировалась как целевой набор цифровых решений для производственных процессов обрабатывающей промышленности. Пик прироста производительности (13,8\% Евросоюз) пришёлся на 2010 год, к которому сформировалась инженерная и инвестиционная осмысленность применения цифровых технологий - облачные, интернет-вещи, чипирование изделий, компонентов и другие. Их влияние прямое - сформировались новые принципы организации производственного процесса и управления таковым, что перевело на новый уровень взаимодействие человека со средствами и предметом труда. Вторично, это значительно повлияло на производственные отношения - поменялась структура требований к знаниям и навыкам персонала. По видению OECD [7] расширение внедрения цифровых решений в обрабатывающей промышленности 


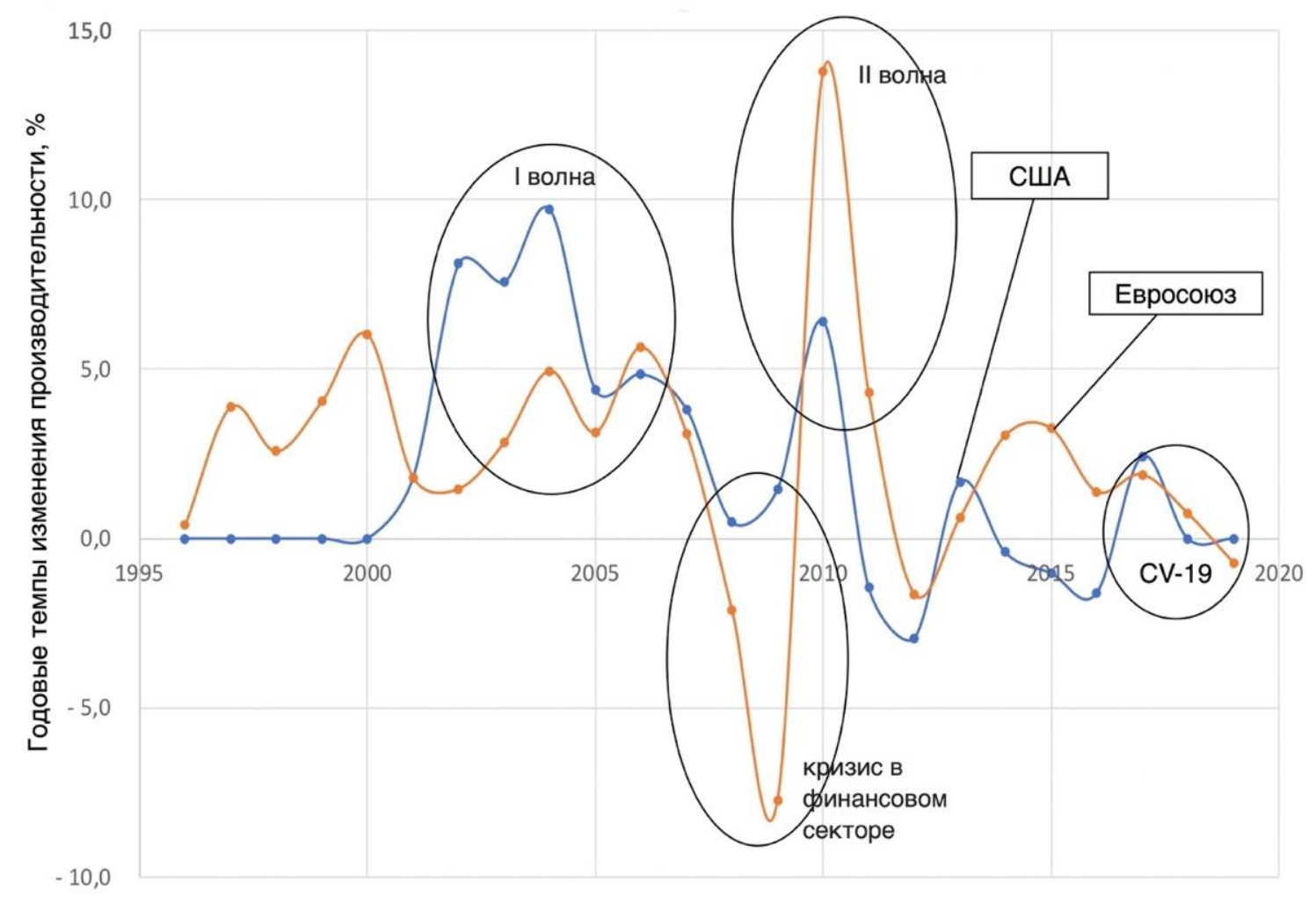

Puc. 1. Циклы (волны) производительности обрабатывающих производств США и Евросоюза. Составлено автором.

Таблица 5. Доля (\%) автоматизированных рабочих мест в обрабатывающей промышленности, фрагмент OECD [7].

\begin{tabular}{|l|l|l|l|l|}
\hline Страны & 2005 & 2010 & 2015 & 2019 \\
\hline Чехия & & 34,81 & 41,05 & 46,97 \\
\hline Дания & & & 62,49 & 100,00 \\
\hline Эстония & 33,52 & 34,86 & 34,50 & 40,46 \\
\hline Финляндия & & 68,57 & 74,69 & 77,98 \\
\hline Греция & 18,41 & 33,84 & & 38,92 \\
\hline Венгрия & & 32,70 & 38,61 & 42,96 \\
\hline Ирландия & & 58,80 & 59,77 & 59,02 \\
\hline Италия & & 41,44 & 46,10 & 54,94 \\
\hline Литва & & 23,15 & 31,67 & 36,64 \\
\hline Нидерланды & & 55,08 & 55,76 & 64,11 \\
\hline Норвегия & 51,40 & 58,89 & 65,46 & 70,33 \\
\hline Польша & 25,47 & 28,27 & 32,47 & 37,32 \\
\hline Португалия & & 30,83 & 32,45 & 35,95 \\
\hline Словакия & 27,42 & 34,96 & 39,16 & 43,09 \\
\hline Словения & 39,28 & 41,41 & 47,68 & 50,49 \\
\hline Испания & & 47,46 & 53,45 & 54,81 \\
\hline Великобритания & & 56,62 & 58,48 & 60,82 \\
\hline
\end{tabular}


сдерживалось и сдерживается дефицитом персонала с требуемым профилем. Авторские наблюдения в рамках национальных предприятий («Приборный завод «ТЕНЗОР», «ТДЛ Текстиль», «Нортек») приводят к тому же выводу о дефиците персонала с требуем набором знаний и навыков для модернизации производственных процессов, перехода к технологиям ненового поколения.

В среднесрочном видении тенденций (2025 год) цифровизации производств обрабатывающей промышленности объективна III волна, которая получила название «Индустрия 4.0». В ее основе полная автоматизация не только производственного, но и всех процессов движения информации и материальных потоков (Kagermann Н. и др. [14]). Персонал управляет полностью автоматизированным комплексом от приема заказа до доставки потребителю готовой продукции, а принципами организации производственного процесса определяется «...связность, модульность, комплексное проектирование («end-to-end engineering») и персонал» (Snell S.A. [15]). Причем квалификационные требования к персоналу, его функция в организации процесса претерпит значительные структурные изменения, что вызовет радикальную трансформацию производственных отношений в обрабатывающей промышленности.

Глобальная консолидация, инновационность спроса и цифровизация производственного и обеспечивающих процессов - таков основной внешний контур развития обрабатывающей промышленности в среднесрочной перспективе. Компиляция трех представленных тенденций, их совмещенный анализ, приводит автора к видению генеральной экономической директивы развития обрабатывающей промышленности, которую можно сформулировать как трансформация производственных отношений. Соответственно, необходима не только технологическая (инженерная) готовность к новым способам организации производства, интеграция в мировые вертикальные цепи, нацеленность на технологические инновации, долгосрочное планирование, но и подготовка персонала с новой картой профиля знаний и навыков. Именно последнее будет обеспечивать конкурентоспособность обрабатывающей промышленности в среднесрочной перспективе.

\section{Библиографический список}

1. Ивантер В.В. Экономика по академику Ивантеру. Авторский сборник / Институт народнохозяйственного прогнозирования Российской академии наук. Москва, 2020.

2. Chryssolouris, G., Mavrikios, D., Mourtzis, D. Manufacturing Systems: Skills \& Competencies for the Future. Procedia CIRP, 7, 2013, 17-24.

3. The future of global manufacturing, CBRE Research, 2017. Электронный документ. Режим доступа: https://www. cbre.com 21.0672020 .

4. Global Manufacturing Outlook. Transforming for a digitally connected future, KРMG, 2018. Электронный документ. Режим доступа: https://assets.kpmg/content/dam/kpmg/xx/pdf/2018/06/global-manufacturing-outlook. pdf 20.06.2020.

5. 2020 Manufacturing Industry Outlook. Exploring manufacturing trends, Delloite, 2019. Электронный документ. Режим доступа: https:/www2.deloitte.com/content/dam/Deloitte/us/Documents/energy-resources/ us-2020-manufacturing-outlook.pdf 20.06.2020.

6. Manufacturing for Growth. Strategies for Driving Growth and Employment. World Economic Forum Report in collaboration with Deloitte Touche Tohmatsu Limited, 2013. Электронный документ. Режим доступа: httр:// www3.weforum.org/docs/WEF_ManufacturingForGrowth_ExecutiveSummary_2013.pdf 8.06.2020.

7. OECD Science, Technology and Industry Scoreboard 2017: The digital transformation, OECD Publishing, Paris, 2017.

8. Science, research and innovation performance of the EU, 2018. Strengthening the foundations for Europe's future. EU publications, 2019. Электронный документ. Режим доступа: https://op.europa.eu/en/publication-detail/-/ publication/16907d0f-1d05-11e8-ac73-01aa75ed71a1/language-en 23.04.2020.

9. Фомина Н.Е., Алексеев А. А. К вопросу о взаимосвязи консолидации и инновационности отраслей и рынков: статистический эксперимент. Экономика и социология. 2018. № 37. С. 27-30.

10. Hult, G.T.M., Ketchen, D.J., Jr. Does market orientation matter? A test of the relationship between positional advantage and performance. Strategic Management Journal, 22, 2001, 899-906. 
11. The Global Technology Revolution 2020, In-Depth Analyses. Bio/Nano/Materials/Information Trends, Drivers, Barriers, and Social Implications. Richard Silberglitt, Philip S. Antón, David R. Howell, Anny Wong etc., RAND Corporation, 2006. Электронный документ. Режим доступа: https://www.rand.org/content/dam/rand/pubs/ technical_reports/2006/RAND_TR303.pdf 20.06.20.

12. Алексеев А.А., ФоминаН.Е., Маркевич С.В. Структура инвестирования промышленных инноваций. Экономические науки. 2012. № 96. С. 121-125.

13. Rai, A., Patnayakuni, R., Seth, N. Firm performance impacts of digitally enabled supply chain integration capabilities. MIS Quarterly: Management Information Systems, 30 (2), 2006, pp. 225-246.

14. Kagermann H., Wahlster W., Helbig J. eds., Recommendations for implementing the strategic initiative Industrie 4.0: Final report of the Industrie 4.0 Working Group, 2013.

15. Snell, S.A., \& Dean, J.W. Integrated Manufacturing and Human Resource Management: A Human Capital Perspective. Academy of Management Journal, 35(3), 1992. 